Article

\title{
Hyperthermia Using Antibody-Conjugated Magnetic Nanoparticles and Its Enhanced Effect with Cryptotanshinone
}

\author{
Satoshi Ota $^{1}$, Naoya Yamazaki ${ }^{1}$, Asahi Tomitaka ${ }^{2}$, Tsutomu Yamada ${ }^{1}$ and Yasushi Takemura ${ }^{1, *}$ \\ 1 Department of Electrical and Computer Engineering, Yokohama National University, \\ Yokohama 240-8501, Japan; E-Mails: ota-satoshi-gw@ynu.jp (S.O.); \\ yamazaki-naoya-vr@ynu.ac.jp (N.Y.); yamada@ynu.ac.jp (T.Y.) \\ 2 Department of Materials Science and Engineering, University of Washington, Seattle, WA 98195, \\ USA; E-Mail: tomitaka@u.washington.edu \\ * Author to whom correspondence should be addressed; E-Mail: takemura@ynu.ac.jp; \\ Tel./Fax: +81-45-339-4154.
}

Received: 17 February 2014; in revised form: 9 April 2014 / Accepted: 17 April 2014 / Published: 23 April 2014

\begin{abstract}
Heat dissipation by magnetic nanoparticles (MNPs) under an alternating magnetic field can be used to selectively treat cancer tissues. Antibodies conjugated to MNPs can enhance the therapeutic effects of hyperthermia by altering antibody-antigen interactions. $\mathrm{Fe}_{3} \mathrm{O}_{4}$ nanoparticles (primary diameter, 20-30 nm) coated with polyethylenimine (PEI) were prepared and conjugated with $\mathrm{CH} 11$, an anti-Fas monoclonal antibody. HeLa cell growth was then evaluated as a function of antibody and MNP/antibody complex doses. HeLa cell growth decreased with increased doses of the antibody and complexes. However, MNPs alone did not affect cell growth; thus, only the antibody affected cell growth. In hyperthermia experiments conducted using an alternating magnetic field frequency of $210 \mathrm{kHz}$, cell viability varied with the intensity of the applied alternating magnetic field, because the temperature increase of the culture medium with added complexes was dependent on magnetic field intensity. The HeLa cell death rate with added complexes was significantly greater as compared with that with MNPs alone. Cryptotanshinone, an anti-apoptotic factor blocker, was also added to cell cultures, which provided an additional anti-cancer cell effect. Thus, an anti-cancer cell effect using a combination of magnetic hyperthermia, an anti-Fas antibody and cryptotanshinone was established.
\end{abstract}

Keywords: magnetic nanoparticles; hyperthermia; antibody; apoptosis; cryptotanshinone 


\section{Introduction}

Magnetic nanoparticles (MNPs) can be used in various medical fields as carriers for a drug delivery system (DDS), as contrast agents for magnetic resonance imaging and as heat sources for hyperthermia [1-3]. Magnetic capsules that encapsulate drugs and avoid loss due to elution in blood vessels have been synthesized as carriers for a DDS [4]. Synthesizing MNPs for use in a DDS and for hyperthermia has also been investigated. In particular, iron oxide nanoparticles, such as $\mathrm{Fe}_{3} \mathrm{O}_{4}$, have low cytotoxicity and have been investigated for their magnetic property with respect to the effects of their primary and secondary sizes, states and surface-modifying agents [5-7].

Hyperthermia is a less invasive method for cancer therapy, and tumor cells are more susceptible to heat than healthy cells. The clinical effects of hyperthermia using MNPs have been demonstrated for prostate cancer [8]. A magnetic field can be used to direct MNPs to a disease site to treat a deeply embedded tumor. MNPs are heated by applying an AC magnetic field of sufficient strength and frequency. Hyperthermia using MNPs is not restricted due to the unacceptable coincidental heating of healthy tissues, because MNPs can be used to selectively heat cancer tissues [2]. Tumor growth could be controlled in mouse $\mathrm{C} 3 \mathrm{H}$ mammary carcinoma using hyperthermia treatment with superparamagnetic nanoparticles and excitation with an AC magnetic field [9]. Hyperthermia-induced apoptosis has been observed in human Raji cells, as confirmed by apoptosis-associated DNA fragmentation [10]. In addition, the integrative therapeutic and diagnostic application, called theranostics, has emerged. MNPs have been used both as a heat source for hyperthermia and as a contrast agent for magnetic resonance imaging (MRI) [11-13]. For in vivo applications, polyethylene glycol (PEG) is coated onto MNPs in order to avoid the reticuloendothelial system, due to opsonin absorbance onto MNPs and phagocytosis by macrophages $[12,13]$.

It has been reported that an interactive therapy is synergistic, additive or antagonistic [14]. It is synergistic or additive when the effect of the combination is higher than each single effect or equal to each other, respectively. In contrast, it is antagonistic when the effect of the combination is lower than each single effect and non-interactive. The combined use of MNPs and antibodies increases these therapeutic effects. Antibody targeting of tumor-associated antigens (TAA) enhances the selective effects in cancer tissues [15]. Using G250 antibody-conjugated magnetoliposomes, MNPs encased in neutral liposomes were used to target renal cell carcinoma and were suitable for efficient hyperthermia treatment [16]. Ch11 is a monoclonal antibody directed against Fas, which is a cell surface protein that belongs to the tumor necrosis factor (TNF) receptor family and induces cellular apoptosis [17]. Apoptosis induced by anti-Fas antibodies is indistinguishable from the cytolytic activity of TNF [18]. Target cells undergo apoptosis when the Fas ligand (FasL) binds to Fas [17]. Fas stimulation induces both caspase-8-dependent and -independent activation of Bak, a pro-apoptotic member of the Bcl-2 family [19,20]. An anti-Fas antibody mimicked the function of FasL and induced target cells apoptosis [21,22]. It has also been shown that CH11 could induce HeLa cell apoptosis [20].

For this study, polyethylenimine (PEI)-coated $\mathrm{Fe}_{3} \mathrm{O}_{4}$ nanoparticles were prepared and then conjugated with $\mathrm{CH} 11$ antibodies. PEI modifications disperse MNPs due to cationic PEI charges and the antibody interfaces with MNPs. HeLa cell growth in the presence of MNPs, CH11 antibodies and $\mathrm{MNP} /$ antibody complexes was then evaluated. Cell growth as a function of antibody and complex dose was also assessed. For hyperthermia experiments using these complexes, cell viability was determined 
as a function of $\mathrm{AC}$ magnetic field intensity. In addition, cryptotanshinone, which induces anti-tumor activity, was added to cell cultures in conjunction with hyperthermia and antibody treatment. Cryptotanshinone, the major tanshinone isolated from Salvia miltiorrhiza Bunge, effectively blocks the expression of Bcl-2, an anti-apoptotic member of the Bcl-2 family, and promotes cellular apoptosis [23].

\section{Results and Discussion}

\subsection{HeLa Cell Growth in the Presence of CH11 Antibody or MNP/Antibody Complexes}

Figure 1 shows HeLa cell growth over three days after adding a $\mathrm{CH} 11$ antibody. Cell numbers were normalized by the number of cells in the absence of antibody. HeLa cell growth was dependent on antibody dose. After one day in the presence of $\mathrm{CH} 11$ antibodies, cell growth was reduced by $60 \%$ or more. With $1.0 \mu \mathrm{g} / \mathrm{mL}$ of antibody, cell growth was $30 \%$ of the control. At three days, cells with $1.0 \mu \mathrm{g} / \mathrm{mL}$ of antibody lost their ability to form colonies (Figure 2). This indicated that the CH11 antibody induced cellular apoptosis [20,24].

Figure 1. HeLa cell growth in the presence of a CH11 antibody added at 0.2, 0.5 and $1.0 \mu \mathrm{g} / \mathrm{mL}$. The control did not include this antibody. Cell numbers were normalized by the number of control cells. Cell numbers decreased with increased antibody dose.

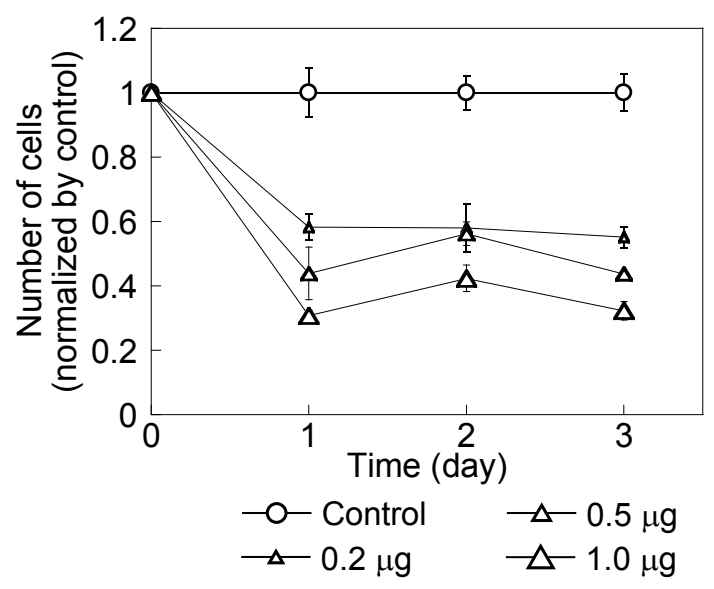

Figure 2. Images of HeLa cells without (a) and with (b) a CH11 antibody at $1.0 \mu \mathrm{g} / \mathrm{mL}$. There were fewer cells after adding this antibody compared with those without this antibody.
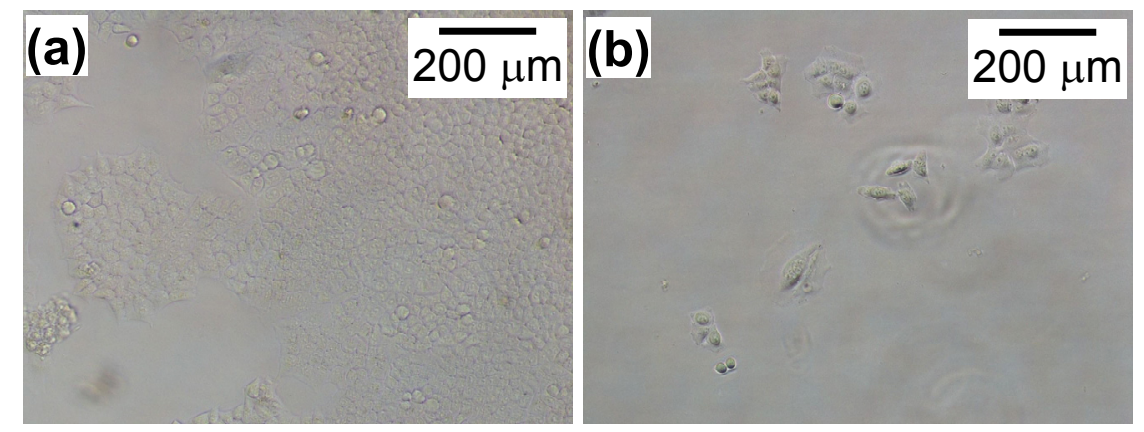
Figure 3 shows HeLa cell growth in the presence of PEI-coated MNPs or MNP/antibody complexes for three days. Cell numbers were normalized to the number of cells without MNPs and complexes. PEI-coated MNPs did not affect cell growth. However, cell growth decreased with an increased dose of these complexes. Figure 4 shows that cells with added complexes lost their ability to form colonies compared with the control and when PEI-coated MNPs were added.

Figure 5 shows TIG-1 cell (human lung fibroblast line) growth in the presence of PEI-coated MNPs or the complexes for three days. Cell numbers were normalized to the number of cells without MNPs and complexes. For TIG-1 cells, these complexes only minimally affected cell growth, because the antibody used selectively targeted TAA [15].

Figure 3. HeLa cell growth in the presence of polyethylenimine (PEI)-coated magnetic nanoparticles (MNPs) at $300 \mu \mathrm{g} / \mathrm{mL}$ and with MNP/antibody complexes added at 100, 200 and $300 \mu \mathrm{g} / \mathrm{mL}$. The control did not include these treatments. Cell numbers were normalized by the number of control cells. Cell numbers decreased with increasing complex doses.

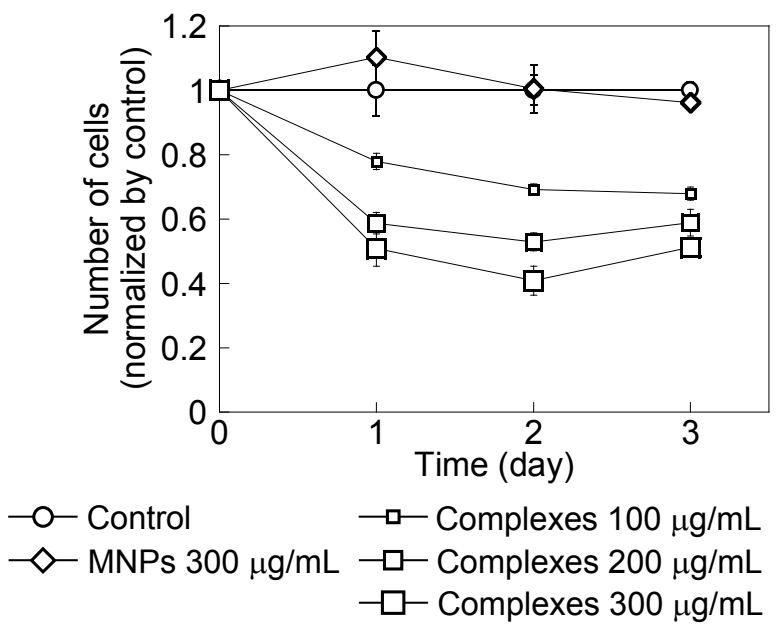

Figure 4. Images of HeLa cells with (b) PEI-coated MNPs added at $300 \mu \mathrm{g} / \mathrm{mL}$ or (c) MNP/antibody complexes added at $300 \mu \mathrm{g} / \mathrm{mL}$. The image in (a) is of the control cells in Figure 1. There were fewer cells after adding PEI-coated MNPs and complexes compared to without these treatments.

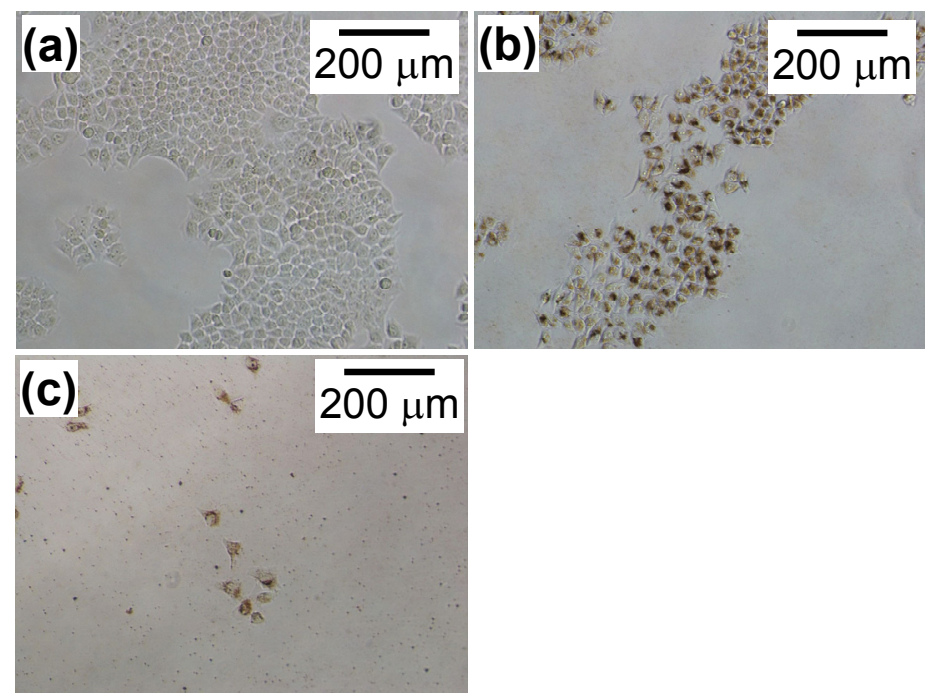


Figure 5. TIG-1 cell growth in the presence of PEI-coated MNPs at $300 \mu \mathrm{g} / \mathrm{mL}$ and with MNP/antibody complexes at 100, 200 and $300 \mu \mathrm{g} / \mathrm{mL}$. The control did not include these treatments. Cell numbers were normalized to the number of control cells.

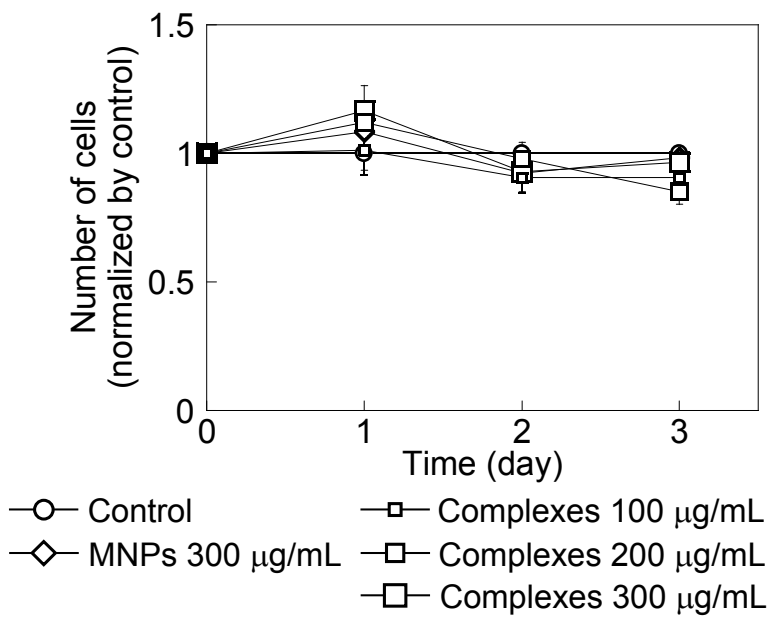

\subsection{Effect of Magnetic Hyperthermia Combined with CH11 Antibodies}

The temperature increase in the culture medium was dependent on the magnetic field intensity used (Figure 6). The temperature of the medium after applying the magnetic fields of 210, 230 and 250 Oe for 30 min was $40.3,42.8$ and $46.2^{\circ} \mathrm{C}$, respectively. When applying an AC magnetic field of $>230$ Oe, the temperature was $>42.0^{\circ} \mathrm{C}$. The medium that contained MNPs in a 35-mm dish was measured using a fiber-optic thermometer while applying an AC magnetic field. Temperatures of $>42.0^{\circ} \mathrm{C}$ can cause sublethal damage to HeLa cells [25]. Conjugating CH11 antibodies to PEI-coated MNPs did not influence the increase in temperature.

Figure 7 shows cell viability results when adding PEI-coated MNPs or the complexes and applying an $\mathrm{AC}$ magnetic field for $1 \mathrm{~h}$. The decrease in cell viability was minimal with a magnetic field intensity of $210 \mathrm{Oe}$, because the temperature of the heat generated was $<42.0{ }^{\circ} \mathrm{C}$. However, cell viability decreased with a magnetic field intensity of $230 \mathrm{Oe}$, and the decrease was significant with 250 Oe. In particular, cell death was significant when adding the complexes and applying AC magnetic field intensities of 230 and 250 Oe. This indicated that this antibody had enhanced the therapeutic effect of hyperthermia, because of its selective anti-tumor effect by interacting with TAA [15]. However, it was not examined if this anti-cancer effect was induced by the increase of the hyperthermic effect, due to the cancer-targeting effect of the complexes in this study. PEI-coated MNPs accumulated on the cell surface without antibody. Accumulation of PEI-coated MNPs was observed by phase contrast microscopy. Figure 8 shows that those cells with reduced viability in Figure 7 had lost their ability to form colonies. The combined effect of magnetic hyperthermia with this antibody indicated in Figure 7 was in good agreement with the images shown in Figure 8. It was not examined and discussed whether this anti-cancer effect derived from apoptosis or necrosis. 
Figure 6. The temperature rise of culture medium added with PEI-coated MNPs of $200 \mu \mathrm{g} / \mathrm{mL}$ in the case of applying an AC magnetic field for $30 \mathrm{~min}$. The magnetic field intensity was 210,230 and 250 Oe. The frequency of magnetic field was $210 \mathrm{kHz}$. The control indicates the sample added with nothing in the case of applying the AC magnetic field of 250 Oe. MNPs were effective in hyperthermia. The temperature rise depended on AC magnetic field intensity.

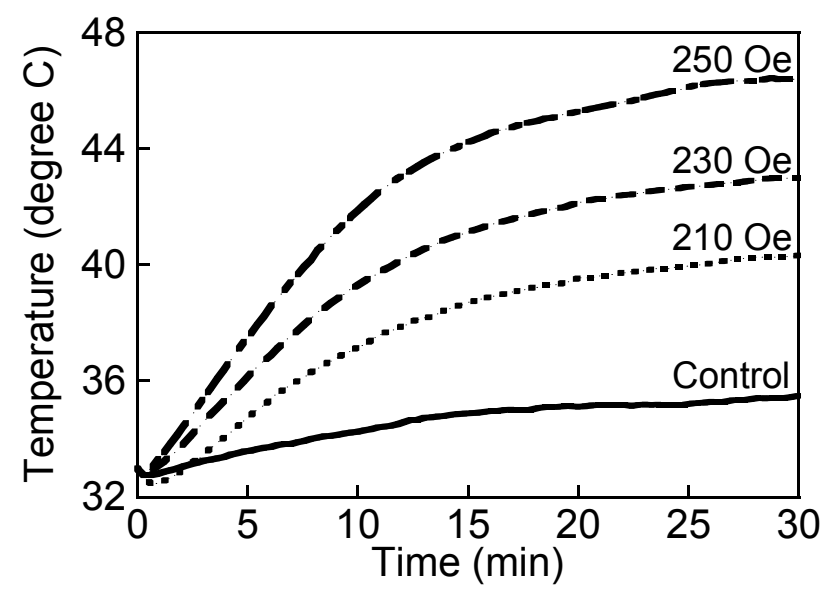

Figure 7. HeLa cell viability with added PEI-coated MNPs or MNP/antibody complexes and the application of an AC magnetic field for $1 \mathrm{~h}$. The magnetic field intensities were 210, 230 and 250 Oe. The AC magnetic field frequency was $210 \mathrm{kHz}$. The control did not include MNPs or complexes while applying an AC magnetic field of 250 Oe. Cell viability decreased with increased magnetic field intensity. The complexes decreased cell viability compared with PEI-coated MNPs. The confirmation of cell viability decrease by adding the complexes in each magnetic field is marked with an asterisk $(p<0.05)$.

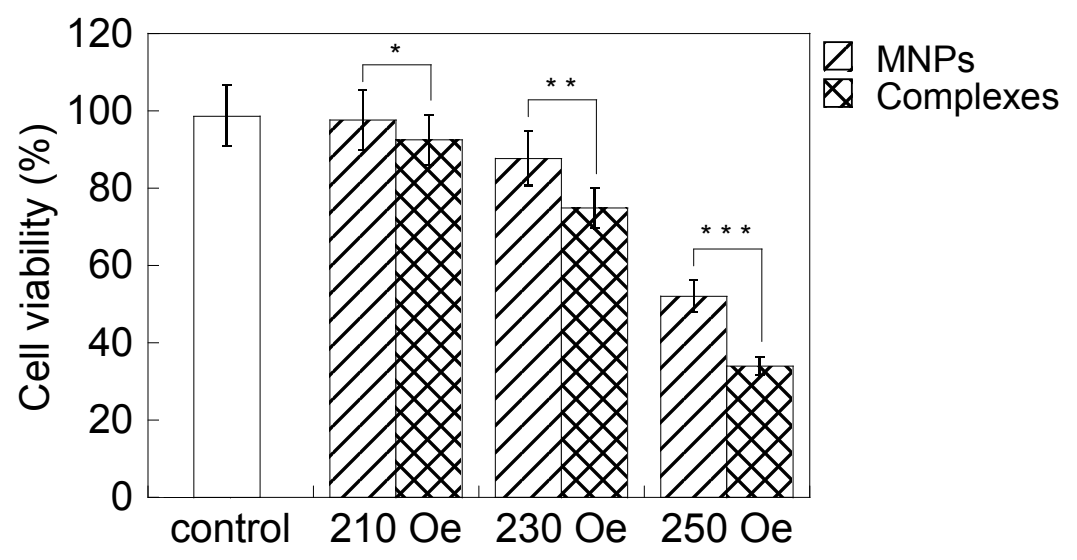


Figure 8. Images of HeLa cells in the presence of PEI-coated MNPs or MNP/antibody complexes and the application of an AC magnetic field for $1 \mathrm{~h}$. Cell conditions and magnetic field intensities were: (b) PEI-coated MNPs and 210 Oe; (c) PEI-coated MNPs and $250 \mathrm{Oe}$; (d) complexes and $210 \mathrm{Oe}$; and (e) complexes and $250 \mathrm{Oe}$. The image in (a) is of the control cells in Figure 7. The AC magnetic field frequency was $210 \mathrm{kHz}$. The clusters in (c) and (e) are cell colonies. Cells had adhered and formed large colonies in (a), (b) and (d). However, cells were divided into a number of small colonies in (c) and (e).

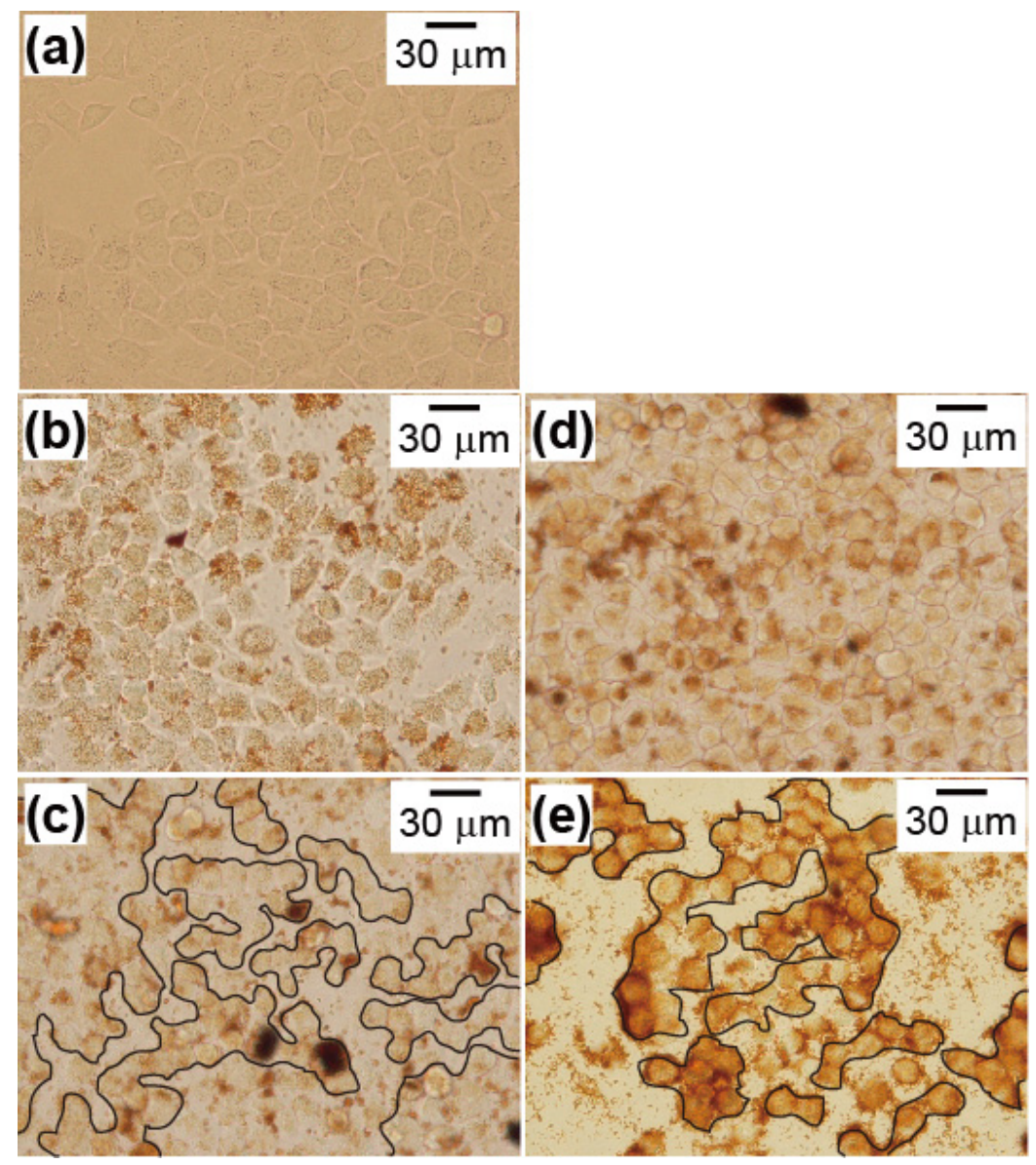

\subsection{Cryptotanshinone-Induced Cellular Apoptosis}

Cell viability was significantly reduced with the combination of cryptotanshinone with hyperthermia and antibody compared with the hyperthermia treatment combined with antibody (Figure 9). Bcl-2 is expressed in response to apoptotic stimuli, such as irradiation and anti-cancer drugs [19]. Cytochrome c release from mitochondria is downregulated by Bcl-2 [26]. Cytochrome c induces caspase-mediated apoptosis [27]. Cryptotanshinone inhibits Bcl-2 expression by inhibiting mitogen-activated protein kinase (MAPK) activity, and apoptosis is promoted by the unregulated release of cytochrome c [23,27]. It was found that the cell growth and cell number were not affected by cryptotanshinone. Cryptotanshinone itself does not promote cell death, as its effect is limited to controlling the expression of anti-apoptotic proteins. Cell survival declined to $12 \%$ when the complexes along with cryptotanshinone were added and a magnetic field intensity of 250 Oe (culture medium temperature, $46.2{ }^{\circ} \mathrm{C}$ ) was used. This showed that cryptotanshinone significantly contributed to the anti-cancer cell effects of magnetic hyperthermia and antibody treatment. 
Figure 9. HeLa cell viability in the presence of PEI-coated MNPs, MNP/antibody complexes or MNP/antibody complexes and cryptotanshinone (CP) and when applying an AC magnetic field for $1 \mathrm{~h}$. The magnetic field intensities were 230 and 250 Oe. The AC magnetic field frequency was $210 \mathrm{kHz}$. Cryptotanshinone effectively reduced cell viability.

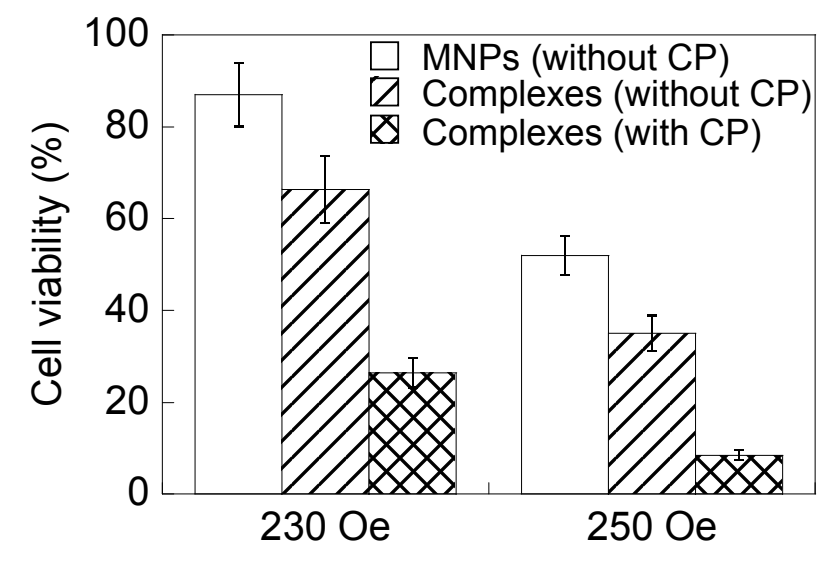

\section{Experimental Section}

\subsection{Materials and Reagents}

$\mathrm{Fe}_{3} \mathrm{O}_{4}$ nanoparticles (primary diameter, 20-30 nm) were obtained from Nanostructured and Amorphous Materials, Inc. Polyethylenimine max (PEI; mw 40,000) was from Polysciences, Inc. Monoclonal antibody CH11, $N$-succinimidyl 3-(2-pyridyldithio)propionate (SPDP), 2-iminothiolane hydrochloride and cryptotanshinone were from Immunotech S.A. (Marseille, Freance), Pierce Thermo Scientific K.K. (Rockford, IL, USA), Nacalai Tesque (Kyoto, Japan) and Carbosynth Ltd. (Berkshire, UK), respectively. SPDP and 2-iminothiolane hydrochloride were used to modify PEI and CH11, respectively. SPDP is a cross-linking agent that conjugates amino groups with thiol groups through disulfide bonds. To conjugate an antibody to PEI-coated MNPs, PEI amino groups on the surfaces of MNPs were modified using SPDP. Antibody amino groups were modified using 2-iminothiolane hydrochloride and substituted with thiol groups.

\subsection{Surface Coating and Synthesis of MNP/Antibody Complexes}

$\mathrm{Fe}_{3} \mathrm{O}_{4}$ nanoparticles $(100 \mathrm{mg})$ were dispersed in $25 \mathrm{~mL}$ of a PEI solution $(0.2 \mathrm{mg} / \mathrm{mL})$ by supersonification for $10 \mathrm{~min}$. This solution was then centrifuged at $743 \times g(R=7.39 \mathrm{~cm})$ for $15 \mathrm{~min}$. The supernatant was centrifuged at $10,000 \times g(R=8.8 \mathrm{~cm})$ for $30 \mathrm{~min}$, and the precipitate was collected as PEI-coated $\mathrm{Fe}_{3} \mathrm{O}_{4}$ nanoparticles.

PEI-coated $\mathrm{Fe}_{3} \mathrm{O}_{4}$ nanoparticles were dispersed in $1 \mathrm{~mL}$ of phosphate-buffered saline (PBS), mixed with $25 \mu \mathrm{L}$ of an SPDP solution [SPDP at $20 \mathrm{mM}$ in Dimethyl sulfoxide (DMSO)] for 30 min and then centrifuged at $10,000 \times g(R=8.8 \mathrm{~cm})$ at room temperature for $30 \mathrm{~min}$. The precipitate was collected as SPDP-modified PEI-coated $\mathrm{Fe}_{3} \mathrm{O}_{4}$ nanoparticles. These were dispersed in $1 \mathrm{~mL}$ of PBS.

The CH11 antibody (50 $\mu \mathrm{g})$ was dissolved in $1 \mathrm{~mL}$ of PBS, and $18 \mu \mathrm{L}$ of a 2 -iminothiolane hydrochloride solution $(2 \mathrm{mg} / \mathrm{mL})$ was added at room temperature for $1 \mathrm{~h}$. SPDP-modified PEI-coated $\mathrm{Fe}_{3} \mathrm{O}_{4}$ nanoparticles were mixed with 2-iminothiolane hydrochloride modified $\mathrm{CH} 11$ at room 
temperature for $12 \mathrm{~h}$. This solution was then centrifuged at $10,000 \times g(R=8.8 \mathrm{~cm})$ at room temperature for $30 \mathrm{~min}$. The precipitate was collected as $\mathrm{CH} 11$-conjugated $\mathrm{Fe}_{3} \mathrm{O}_{4}$ nanoparticles (MNP/antibody complexes). Conjugation of $\mathrm{Fe}_{3} \mathrm{O}_{4}$ nanoparticles with antibody was confirmed by the BCA protein assay. The size distribution of PEI-coated $\mathrm{Fe}_{3} \mathrm{O}_{4}$ nanoparticles and the complexes in (PBS) are shown in Figure 10. Comparing the results in Figure 3 with those in Figure 1, the cell growth inhibitory effect of the antibody at $0.2 \mu \mathrm{g} / \mathrm{mL}$ was confirmed using the complexes at $200 \mu \mathrm{g} / \mathrm{mL}$. The number of molecules of the antibody bound to a MNP was calculated to $1.2 \times 10^{3}$ by the above result and the size of PEI-coated MNPs dispersed in PBS.

Figure 10. The size distribution of PEI-coated $\mathrm{Fe}_{3} \mathrm{O}_{4}$ nanoparticles and the complexes in phosphate-buffered saline (PBS). The size of PEI-coated $\mathrm{Fe}_{3} \mathrm{O}_{4}$ nanoparticles and the complexes were $318 \pm 57 \mathrm{~nm}$ and $349 \pm 70 \mathrm{~nm}$, respectively.

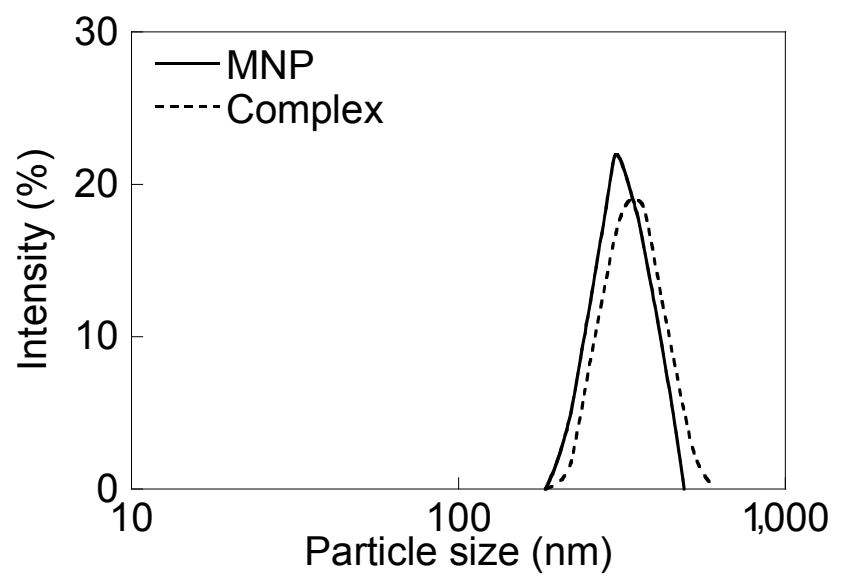

\subsection{Cell Culture}

HeLa cells (human cervical carcinoma line) and TIG-1 cells (human lung fibroblast line) were cultured in Dulbecco's modified Eagle medium (DMEM) supplemented with 10\% fetal bovine serum (FBS) and 1\% penicillin-streptomycin (PS).

\subsection{Cell Growth Inhibition}

HeLa cells and TIG-1 cells were cultured in a 24-well plate at a density of 10,000 cells/well for $24 \mathrm{~h}$. For experimental treatments, the following were also added to the wells: CH11 antibody at 0.2, 0.5 or $1.0 \mu \mathrm{g} / \mathrm{mL}$; PEI-coated MNPs at $300 \mu \mathrm{g} / \mathrm{mL}$; or MNP/antibody complexes at 100,200 or $300 \mu \mathrm{g} / \mathrm{mL}$. Cell numbers were counted every day for 3 days after these different treatments.

\subsection{Hyperthermia and Cryptotanshinone Treatment}

To evaluate cell viability after hyperthermia treatment, cells were cultured in $35-\mathrm{mm}$ dishes at a density of 50,000 cells/well for $24 \mathrm{~h}$. The culture medium that contained PEI-coated MNPs or complexes at $200 \mu \mathrm{g} / \mathrm{mL}$ was prepared at $37^{\circ} \mathrm{C}$. This medium $(2.5 \mathrm{~mL})$ was added to a cell culture. One day after adding MNPs to the cell culture, an AC magnetic field was applied for $1 \mathrm{~h}$. The magnetic field intensities used were 210, 230 and $250 \mathrm{Oe}$, and the AC magnetic field frequency was 
$210 \mathrm{kHz}$. Cells were incubated for $24 \mathrm{~h}$ after heating. Cell viability was evaluated by trypan blue exclusion. For combinations of hyperthermia using MNP/antibody complexes and cryptotanshinone, cryptotanshinone was added to the culture medium at a final concentration of $0.3 \mathrm{mg} / \mathrm{mL}$. The medium with cryptotanshinone $(2.5 \mathrm{~mL})$ was added to cells for $15 \mathrm{~min}$ before adding PEI-coated MNPs and the complexes. When using these combinations with cryptotanshinone, the AC magnetic field intensities used were 230 and 250 Oe. In addition, both intracellular and extracellular PEI-coated MNPs were confirmed by Prussian blue staining. A smaller number of intracellular MNPs in cytoplasm were observed than extracellular MNPs on the cell surface. This probably indicated that the large number of MNPs were not internalized into cells, due to aggregation. Aggregation was induced by high concentration of MNPs.

\section{Conclusions}

The anti-cancer effects of magnetic hyperthermia combined with a CH11 antibody and cryptotanshinone were assessed. HeLa cell growth was reduced after treatment with this antibody and MNP/antibody complexes. Hyperthermia generated using PEI-coated MNPs and the application of an AC magnetic field resulted in effective cell death when the magnetic field intensity induced a sufficient temperature increase for killing cancer cells. In addition, hyperthermia treatment using MNP/antibody complexes was quite effective for cancer cell treatment. Moreover, adding cryptotanshinone further reduced HeLa cell survival. Thus, the combination of magnetic hyperthermia, an antibody (CH11; anti-Fas) and cryptotanshinone resulted in a significant anti-cancer cell effect.

\section{Conflicts of Interest}

The authors declare no conflict of interest.

\section{References}

1. Berry, C.C.; Adam, A.S.G. Functionalisation of magnetic nanoparticles for application in biomedicine. J. Phys. D 2003, 36, R198-R206.

2. Pankhurst, Q.A.; Connolly, J.; Jones, S.K; Dobson, J. Applications of magnetic nanoparticles in biomedicine. J. Phys. D 2003, 36, R167-R181.

3. Kozissnik, B.; Bohorquez, A.C.; Dobson, J.; Rinaldi, C. Magnetic fluid hyperthermia: Advances, challenges, and opportunity. Int. J. Hyperthermia 2013, 29, 706-714.

4. Fuchigami, T.; Kawamura, R.; Kitamoto, Y.; Nakagawa, M.; Namiki, Y. Ferromagnetic FePt-nanoparticles/polycation hybrid capsules designed for a magnetically guided drug delivery system. Langmuir 2011, 27, 2923-2928.

5. Shundo, C.; Zhang, H.; Nakanishi, T.; Osaka, T. Cytotoxicity evaluation of magnetite $\left(\mathrm{Fe}_{3} \mathrm{O}_{4}\right)$ nanoparticles in mouse embryonic stem cells. J. Colloid Surf. B 2012, 97, 221-225.

6. Iida, H.; Takayanagi, K.; Nakanishi, T.; Osaka, T. Synthesis of $\mathrm{Fe}_{3} \mathrm{O}_{4}$ nanoparticles with various size and magnetic properties by controlled hydrolysis. J. Colloid Interface Sci. 2007, 314, 274-280. 
7. Tomitaka, A.; Ueda, K.; Yamada, T.; Takemura, Y. Heat dissipation and magnetic properties of surface-coated $\mathrm{Fe}_{3} \mathrm{O}_{4}$ nanoparticles for biomedical applicaiton. J. Magn. Magn. Mater. 2012, 324, 3437-3442.

8. Johannsen, M.; Gneveckow, U.; Eckelt, L.; Feussner, A.; WaldÖFner, N.; Scholz, R.; Deger, S.; Wust, P.; Loening, S.A.; Jordan, A. Clinical hyperthermia of prostate cancer using magnetic nanoparticles: Presentation of a new interstitial technique. Int. J. Hyperthermia 2005, 21, 637-647.

9. Jordan, A.; Scholz, R.; Wust, P.; Fähling, H.; Felix, R. Magnetic fluid hyperthermia (MFH): Cancer treatment with AC magnetic field induced excitation of biocompatible superparamagnetic nanoparticles. J. Magn. Magn. Mater. 1999, 201, 413-419.

10. Fairbairn, J.J.; Khan, M.W.; Ward, K.J.; Loveridge, B.W.; Fairbairn, D.W.; O’Neill, K.L. Induction of apoptotic cell DNA fragmentation in human cells after treatment with hyperthermia. Cancer Lett. 1995, 89, 183-188.

11. Shubayev, V.I.; Pisanic, T.R., II; Jin, S. Magnetic nanoparticles for theragnostics. Adv. Drug Deliv. Rev. 2009, 61, 467-477.

12. Cole, A.J.; Yang, V.C.; David, A.E. Cancer theranostics: The rise of targeted magnetic nanoparticles. Trends Biotechnol. 2011, 29, 323-332.

13. Hayashi, K.; Nakamura, M.; Sakamoto, W.; Yogo, T.; Miki, H.; Ozaki, S.; Abe, M.; Matsumoto, T.; Ishimura, K. Superparamagnetic nanoparticles clusters for cancer theranostics combining magnetic resonance imaging and hyperthermia treatment. Theranostics 2013, 3, 366-376.

14. Zoil, W.; Ricotti, L.; Tesei, A.; Barzanti, F.; Amadori, D. In vitro preclinical models for a rational design of chemotherapy combinations in human tumors. Crit. Rev. Oncol. Hematol. 2001, 37, 69-82.

15. Duan, Y.; Zheng, J.; Han, S.; Wu, Y.; Wang, Y.; Li, D.; Kong, D.; Yu, Y. A tumor targeted gene vector modified with G250 monoclonal antibody for gene therapy. J. Control. Release 2008, 127, 173-179.

16. Ito, A.; Shinkai, M.; Honda, H.; Kobayashi, T. Medical application of functionalized magnetic nanoparticles. J. Biosci. Bioeng. 2005, 100, 1-11.

17. Nagata, S.; Golstein, P. The Fas death factor. Science 1995, 267, 1449-1456.

18. Yonehara, S.; Ishii, A.; Yonehara, M. A cell-killing monoclonal antibody (anti-Fas) to a cell surface antigen co-downregulated with the receptor of tumor necrosis factor. J. Exp. Med. 1989, 169, 1747-1756.

19. Nagata, S. Apoptosis by death factor. Cell 1997, 88, 355-365.

20. Zhang, L.; Shimizu, S.; Sakamaki, K.; Yonehara, S.; Tsujimoto, Y. A caspase-8-independent signaling pathway activated by Fas ligation leads to exposure of the Bak $\mathrm{N}$ terminus. J. Biol. Chem. 2004, 279, 33865-33874.

21. Itoh, N.; Yonehara, S.; Ishii, A.; Yonehara, M.; Mizushima, S.; Sameshima, M.; Hase, A.; Seto, Y.; Nagata, S. The polypeptide encoded by the cDNA for human cell surface antigen Fas can mediate apoptosis. Cell 1991, 66, 233-243. 
22. Sloand, E.M.; Young, N.S.; Kumar, P.; Weichold, F.F.; Sato, T.; Maciejewski, J.P. Role of Fas ligand and receptor in the mechanism of $\mathrm{T}$-cell depletion in acquired immunodeficiency syndrome: Effect on $\mathrm{CD}^{+}$lymphocyte depletion and human immunodeficiency virus replication. Blood 1997, 89, 1357-1363.

23. Park, I.; Kim, M.; Park, O.J.; Park, M.G.; Choe, W.; Kang, I.; Kim, S.; Ha, J. Cryptotanshinone sensitizes DU145 prostate cancer cells to Fas(APO1/CD95)-mediated apoptosis through Bcl-2 and MAPK regulation. Cancer Lett. 2010, 298, 88-98.

24. Zhang, Y.; Wu, Y.; Cheng, Y.; Zhao, Z.; Tashiro, S.; Onodera, S.; Ikejima, T. Fas-mediated autophagy requires JNK activation in HeLa cells. Biochem. Biophys. Res. Commun. 2008, 377, 1205-1210.

25. Palzer, R.J.; Heidelberger, C. Studies of the quantitative biology of hyperthermic killing of HeLa cells. Cancer Res. 1973, 33, 415-421.

26. Kluck, R.M.; Bossy-Wetzel, E.; Green, D.R.; Newmeyer, D.D. The release of cytochrome c from mitochondria: A primary site for Bcl-2 regulation of apoptosis. Science 1997, 33, 415-421.

27. Yang, J.; Liu, X.; Bhalla, K.; Kim, C.N.; Ibrado, A.M.; Cai, J.; Peng, T.; Jones, D.P.; Wang, X. Prevention of apoptosis by Bcl-2: Release of cytochrome c from mitochondria blocked. Science 1997, 275, 1129-1132.

(C) 2014 by the authors; licensee MDPI, Basel, Switzerland. This article is an open access article distributed under the terms and conditions of the Creative Commons Attribution license (http://creativecommons.org/licenses/by/3.0/). 